\title{
Hypertension frequency in prediabetic patients: single center experience in Eastern Turkey
}

\section{Dogan Nasir Binici, Ozge Timur*, Ahmet Veli Sanibas}

Region Training and Research Hospital, Department of Internal Medicine, Erzurum, Turkey
RECEIVED:

September 22, 2016

ACCEPTED:

October 10, 2016

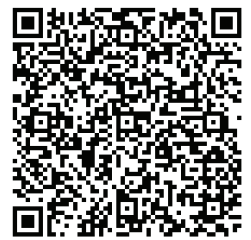

KEYWORDS: hypertension, diabetes, prediabetes

CITATION: Cardiol Croat. 2016;11(10-11):502. | DOI: http://dx.doi.org/10.15836/ccar2016.502

*ADDRESS FOR CORRESPONDENCE: Ozge Timur, Region Training and Research Hospital, Department of Internal Medicine, 25040 Erzurum, Turkey. / Phone: +90442232533 / E-mail: ozgetimur@yahoo.com

ORCID: Dogan Nasir Binici, http://orcid.org/0000-0003-0790-1744 • Ozge Timur, http://orcid.org/0000-0002-7296-5536 Ahmet Veli Sanibas, http://orcid.org/0000-0002-7824-6284

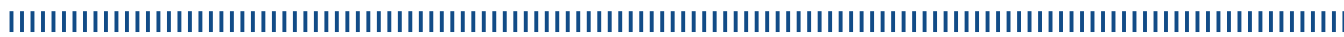

Introduction: High blood pressure is a common condition in society. The prevalence of hypertension (HT) in Turkey is $31.8 \%$ (36.1\% for women and 27.5\% for men). Diabetes mellitus (DM) is the sixth leading cause of death in adults. DM prevalence in Turkey is 13.7\%. HT is a common problem for Type 1 and Type 2 diabetes. ${ }^{1,2}$ Oral glucose tolerance test (OGTT) is recommended for diabetes screening. OGTT results reveals not only in the diagnosis of diabetes also prediabetic conditions such as impaired fasting glucose (IFG) and impaired glucose tolerance (IGT). The aim of this study is to investigate the prevalence of HT in the prediabetic patients.

Patients and Methods: In this study the results of 1000 patients attending to Erzurum (the biggest city in the eastern Turkey) Regional Training and Research Hospital Internal Medicine outpatient clinic, scanned with OGTT for diabetes were examined. Prediabetic patients were evaluated for hypertension.

Results: OGTT results were as follows: 164 (16.4\%) patients with IFG (111 women, 53 men), 129 (12.9\%) patients with IGT (96 women, $33 \mathrm{men}), 161$ (16.1\%) patients with IFG + IGT (108 women, 53 male), 228 (22.8\%) patients with overt diabetes (158 women, 70 men) and 318 (31.8\%) had normal (228 females, 90 males). Considered to be prediabetic IFG, IGT and IFG + IGT groups HT frequency was $40 \%$ (37\% males, $42 \%$ females).

Conclusion: Hypertension is seen more frequently among type 2 DM than normal population. Type 2 DM is seen 2.5 times more than in patients with HT compared with individuals without HT. HT is present about $39 \%$ of newly diagnosed type 2 DM patients. In our study, the prevalence of HT in individuals at risk for development of diabetes is $40 \%$. Blood pressure elevation, with micro and macrovascular disease results in increased morbidity and mortality. In our study the incidence of HT in prediabetic individuals were revealed at close to diabetics. Half of the pre diabetic patients develop diabetes in later years. That's why prediabetes as well as diabetes should be monitored closely. Lifestyle changes and/or medical treatment as metformin, acarbose reduces the risk of diabetes development. Increased awareness of HT in these individuals at risk for development of diabetes, tight blood pressure control is very important in terms of reducing the micro and macro complications.

1. Arici M, Turgan C, Altun B, Sindel S, Erbay B, Derici U, et al; Turkish Society of Hypertension and Renal Diseases. Hypertension incidence in Turkey (HinT): a population-based study. J Hypertens. 2010;28(2):240-4. DOI: http://dx.doi.org/10.1097/HJH.0b013e328332c36b

2. Satman I, Omer B, Tutuncu Y, Kalaca S, Gedik S, Dinccag N, et al; TURDEP-II Study Group. Twelve-year trends in the prevalence and risk factors of diabetes and prediabetes in Turkish adults. Eur J Epidemiol. 2013;28(2):169-80. DOI: http://dx.doi.org/10.1007//10654-013-9771-5 